\title{
Selected issues in diagnostic imaging of spondyloarthritides: psoriatic arthritis and juvenile spondyloarthritis
}

\author{
Iwona Sudoł-Szopińska, Mateusz Płaza, Grzegorz Pracoń \\ Department of Radiology, National Institute of Geriatrics, Rheumatology and Rehabilitation, Warsaw, Poland
}

\begin{abstract}
Spondyloarthritides (also known as spondyloarthropathies) are a group of rheumatic diseases that consists of diversified entities, i.e. ankylosing spondylitis, reactive arthritis, psoriatic arthritis, arthritis in the course of Crohn's disease and ulcerative colitis, and juvenile spondyloarthropathies. In the diagnostics of spondyloarthritides, plain radiography has played a crucial role for years due to its undisputed ability to show distinctive bony changes. Yet as those diseases often manifest themselves by soft tissue pathology and bone marrow inflammation, ultrasonography and magnetic resonance imaging are currently a subject of numerous studies in the quest for setting up diagnostic criteria, especially at early stages of inflammatory processes. In our review, we present an up-to-date insight into classifications, etiopathogenesis and imaging of psoriatic arthritis and juvenile spondyloarthritis.
\end{abstract}

Key words: psoriatic arthritis, juvenile idiopathic arthritis, dynamic magnetic resonance imaging, ultrasonography.

\section{Introduction}

The group of rheumatic diseases comprises numerous inflammatory conditions divided into a dozen or so subgroups with a similar clinical picture as well as laboratory and immunological findings. Diagnostic imaging of these entities is still based mainly on plain radiography. However, other imaging modalities, i.e. ultrasonography (US) and magnetic resonance imaging (MRI), are being used more and more frequently in order to fully understand the pathogenesis of these diseases and to detect them earlier than with radiography.

Ultrasonography and MRI enable detection of early stages of inflammation and assessment of tissues and anatomical regions that are inaccessible or poorly accessible for radiography (subchondral layer of bone tissue, paraspinal tissues, as well as soft tissue of peripheral joints).

Spondyloarthritides (also known as spondyloarthropathies; SpA), i.e. spondylitis with concomitant peripheral arthritis, are the second most common, after systemic connective tissue diseases, group of rheumatic conditions. One of the entities from this group is psoriatic arthritis (PSA), affecting both the appendicular and axial skeleton. It is manifested by arthritis, tenosynovitis and enthesopathy (pathology of tendon and ligament attachments). Moreover, peripheral joint destruction and spinal proliferative changes are typically seen in the course of this disease [1]. The diversified radiographic picture of PsA is well-known to physicians dealing with its diagnosis and treatment. Currently, researchers give special focus to diagnostic utility of US and MRI in early PsA diagnosis.

Juvenile spondyloarthritides (juvenile spondyloarthropathies; JSPA), including their axial forms with involvement of the sacroiliac joints (sacroiliitis) and the spine (spondylitis), are also challenging. In 2009, magnetic resonance was introduced in the diagnostic criteria of sacroiliitis in adults [2], which improved diagnosis of the disease. In children, however, the diagnosis is still based only on radiographs.

In this article we present current research directions concerning the aforementioned issues, aiming at the changes at the distal interphalangeal joint and the nail

\section{Address for correspondence}

Iwona Sudoł-Szopińska, Department of Radiology, National Institute of Geriatrics, Rheumatology and Rehabilitation, Spartanska 1,

02-637 Warsaw, Poland, e-mail: sudolszopinska@gmail.com

Submitted: 26.08.2016; Accepted: 14.12.2016 
in PsA, as well as periarticular inflammation, enthesitis and dactylitis in PSA, advantages of MRI in early diagnosis of JIA, and finally application of dynamic MRI for PSA and JIA diagnosis.

\section{Psoriatic arthritis}

Changes in the course of PSA on radiographs are seen at advanced stages of the disease. Moll and Wright divided them into several types (Table I) which confirm the heterogeneous nature of this disease entity; it affects the peripheral joints, axial spine and sacroiliac joints [3-6] (Fig. 1).

These days Caspar (CASPAR) or Bennet's criteria are of use to diagnose peripheral PSA. Axial PSA is classified in the same manner as ankylosis spondylitis. Skin psoriasis in Bennet's criteria is obligatory to diagnose PsA, while according to Caspar (CASPAR) it is not required. The CASPAR Study Group criteria are also applied in patients with early PsA ( $<24$ months symptom duration) and to control patients with other new-onset inflammatory arthritides. The diagnostic value of CASPAR criteria is higher than Bennet's (sensitivity of 0.914 and specificity of 0.987$)[7,8]$.

Current PsA diagnostic criteria do not mention MRI and US, while both methods may enable detection of early PSA preceding irreversible joint destruction, described in Moll and Wright's classification. The understanding of pathogenetic mechanisms and PSA man- ifestations in imaging at initial stages of the disease contributes to early diagnosis and prompt therapy.

\section{Synovitis and tenosynovitis}

Synovitis, i.e. inflammation of the synovial membrane, is one of the most common pathologies in the course of rheumatic diseases diagnosed with using US and MRI (Fig. 2). This symptom, however, is non-specific since it can be observed in other joint diseases, including osteoarthritis (OA). One of the aims of the current research, employing MRI in particular, is to search for differences in synovitis not only between various pathologies mentioned above, but also between various rheumatic conditions. Certain studies have shown [9] that greater synovial thickening can be expected in

Table I. Five subtypes of PsA according to Moll and Wright [6]

\begin{tabular}{|ll|}
\hline \multicolumn{1}{|c|}{ Subtypes of psoriatic arthritis } \\
\hline 1 & Polyarthritis resembling rheumatoid arthritis \\
\hline 2 & Asymmetrical oligoarthritis \\
\hline 3 & Axial spondyloarthropathy \\
\hline 4 & Predominant distal interphalangeal joint involvement \\
\hline 5 & $\begin{array}{l}\text { Arthritis mutilans associated with destruction and } \\
\text { severe deformity }\end{array}$ \\
\hline
\end{tabular}
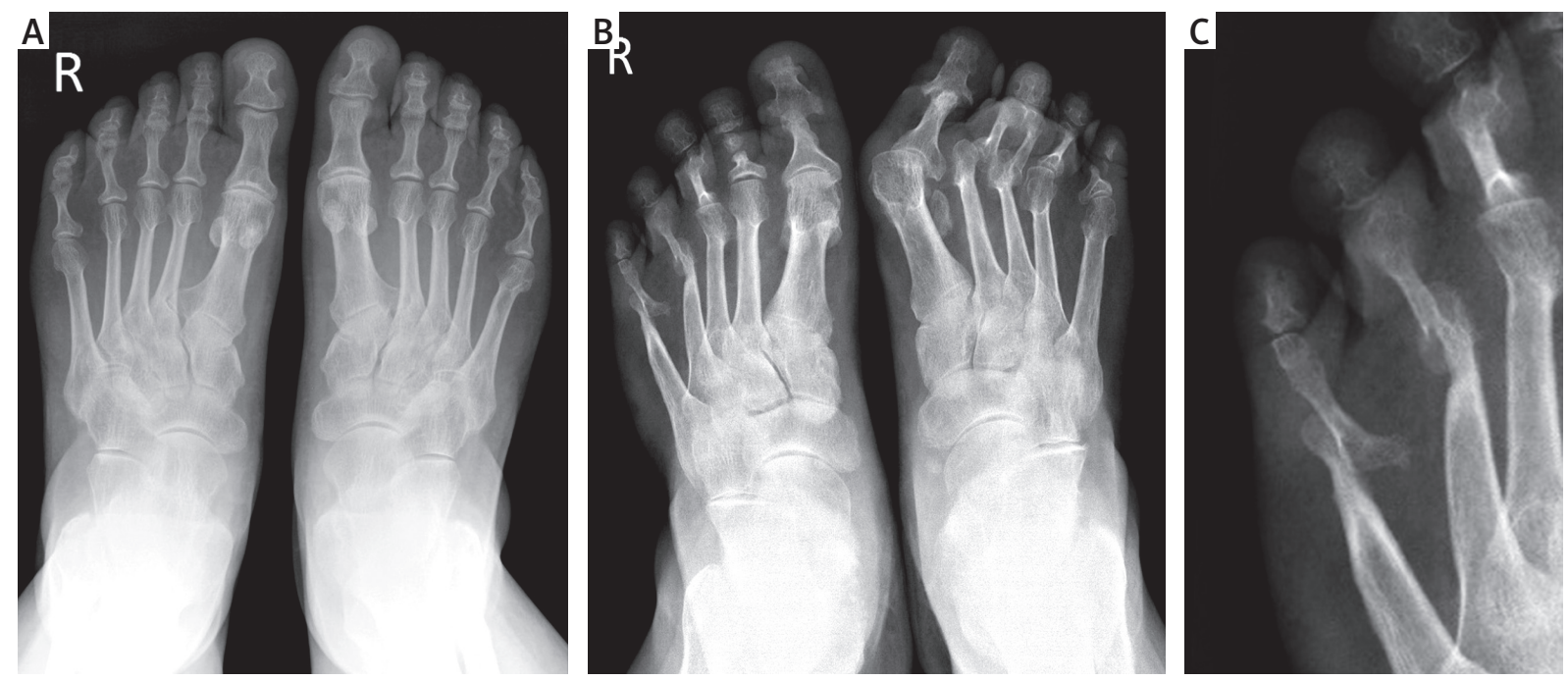

Fig. 1. AP (anterior-posterior) radiograph of the feet performed in 2012 (A), follow-up from 2015 (B) and a magnified image of a follow-up examination of the right $3^{\text {rd }}-5^{\text {th }}$ toes $(C)$ : A) slight inflammatory cysts in the right MTP 1, otherwise the image is within the normal limits; $B, C$ ) luxation of the right MTP 5 and left MTP 3 joints; subluxations of the left MTP 1 and 2 as well as in the right MTP 3 and 4 joints; advanced osteolytic and destructive changes, best seen in the right metatarsophalangeal MTP 4 and 5 joints as well as in the proximal interphalangeal (PIP) joints of the right $2^{\text {nd }}$ toe and left $5^{\text {th }}$ toe; subluxations of the MTP joints of the $2^{\text {nd }}$ and $3^{\text {rd }}$ toes in the left foot and of the $3^{\text {rd }}-5^{\text {th }}$ toes of the right foot. 


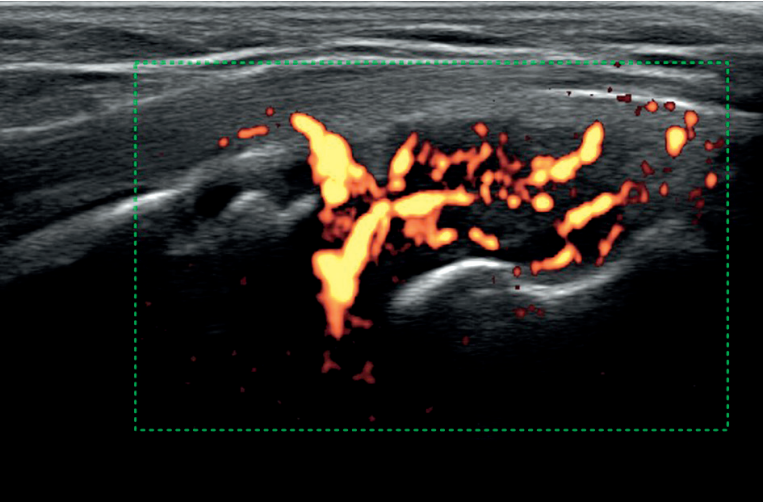

Fig. 2. Ultrasonography: thickened, hypervascularized synovium of the radiocarpal joint.

rheumatoid arthritis (RA) whereas more intensive hypervascularisation can be seen in PsA. Other studies using dynamic contrast enhanced MRI (DCE-MRI) failed to confirm the differences in synovial vascularisation [10, 11]. However, the lack of uniform technique of MRI and its analysis was emphasized (e.g. discrepancies in the location of regions of interest when measuring synovial vascularisation).

Dynamic contrast enhanced MRI can also be used for assessment of inflammatory changes in the bone marrow, which occur in the course of rheumatic diseases, both in the perpendicular and axial skeleton. Studies by Poggenborg et al. [12] have confirmed that DCE-MRI can be used to monitor treatment efficacy.

\section{Changes in the distal interphalangeal joint and nail pathologies}

Inflammatory and post-inflammatory changes at the level of the distal interphalangeal joint (DIP) are typical for PsA. Their direct relation to nail pathologies observed in these patients is being investigated.

To date, it has not been explained which tissues are affected primarily and elicit inflammatory changes in the DIP joint. Studies conducted by various researchers have suggested that these can be enthesitis of the collateral ligaments or the lateral bands of the extensor digitorum tendon, DIP joint arthritis or the DIP joint subchondral bone marrow inflammation. Extensive bone marrow edema is believed by some authors to differentiate PsA from RA [13-15]. This issue requires further, systematic studies, involving MRI and US.

\section{Dactylitis}

Dactylitis, also known as sausage finger, is another distinctive feature of PSA. The pathogenesis, i.e. predilection to one ray in this condition is also unknown.

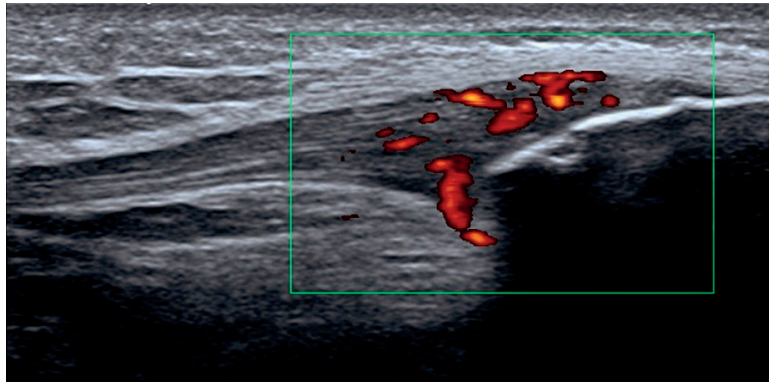

Fig. 3. Ultrasonography: low echogenicity (edema), abnormal echotexture, numerous vessels of the inflammatory-repair process in the tibial enthesis of the iliotibial band, solitary erosion in the bony part of the enthesis.

Magnetic resonance imaging and US enable clear visualization of affected tissues responsible for the thickening of a finger, which is tenosynovitis of the flexor digitorum tendon sheath and/or synovitis of interphalangeal joints of that finger and/or edema, sometimes even with hyperemia of the subcutaneous tissue of that finger.

\section{Periarticular inflammation}

Some authors have suggested that the involvement of periarticular/ extracapsular tissue is typical of PsA [13]. This is another issue that requires explanation since, in the author's own practice (unpublished data), this symptom can also be observed in other rheumatic entities, such as RA and juvenile idiopathic arthritis, most frequently at the level of MCP joints.

\section{Enthesitis}

In multiple publications on rheumatic diseases, enthesitis is believed to be specific for spondyloarthritides. This issue is still under research and several hypotheses published so far propose different mechanisms which might explain that feature [16-18]. The spectrum of changes observed in patients with a clinical diagnosis of enthesitis in MRI and power Doppler ultrasound is identical to that observed in the course of degenerative changes or microinjuries in healthy controls [19-21] (Fig. 3). This particularly applies to entheses of the lower limbs and pelvis, which are prone to considerable overload.

\section{Juvenile spondyloarthritis}

By contrast with adults, children with juvenile spondyloarthritides (juvenile spondyloarthritis; JSpA) rarely present with sacroiliitis and spondylitis, instead peripheral arthritis and enthesitis. Nevertheless, a late diagnosis of the disease affecting sacroiliac joints and the spine leads to severe complications. 
Table II. New York criteria for sacroiliitis [22]

\begin{tabular}{|ll|}
\hline \multicolumn{1}{|c|}{ New York criteria } \\
\hline 0 & Normal image \\
\hline 1 & Blurring of the sacroiliac joint margins \\
\hline 2 & Single erosions and periarticular subchondral sclerosis \\
\hline 3 & $\begin{array}{l}\text { Advanced sacroiliitis, larger and more numerous } \\
\text { erosions, partial ankylosis }\end{array}$ \\
\hline 4 & Complete ankylosis \\
\hline
\end{tabular}

For years, the diagnosis of sacroiliitis in adults as well as children and adolescents has been based on radiography alone, using the New York criteria [2, 21, 22] (Table II).

In 2009, after long international research, the ASAS working group (Assessment of SpondyloArthritis International Society) introduced magnetic resonance imaging to the diagnostic criteria of sacroiliitis in adults [2]. Such a change in the diagnostic algorithm improved considerably detection of the disease.

In the case of children and adolescents, this issue remains open. The diagnosis of axial spondyloarthritis is still based on plain radiography of the sacroiliac joints. Despite studies using MRI of the sacroiliac joints in children with a clinical suspicion of sacroiliitis carried out in several centers worldwide, no diagnostic criteria have been established yet [22-26].

We performed MRI studies in 62 children and adolescents aged 10-18, referred for the examination with a suspicion of sacroiliitis, based on lower back pain (data under preparation). Fifty-five patients have also had radiographs. Changes typical for sacroiliitis on radiographs were present in 16 patients (30\%). However, MRI confirmed features of active inflammation in only one patient (4\%), and signs of chronic inflammation in 4 cases (25\%). Eleven patients (69\%) demonstrated no active or chronic changes indicative of sacroiliitis (Fig. 4).

These preliminary studies have shown that radiography is not reliable not only in adults, which is known [27], but also in children and adolescents. Radiographs in children, which usually involve the pelvic or lumbar area in order to assess the sacroiliac joints, taken with limited radiation exposure due to harmful effects of radiation and radiological protection, are often of inferior quality. This entails a lower diagnostic value compared with adults. Moreover, the assessed regions are frequently obscured by intestinal contents as it is difficult to prepare young patients for the examination.

Magnetic resonance imaging is free from ionizing radiation. It does not require patient preparation since intestinal contents do not superimpose the evaluated structures. Joints require comprehensive assessment in
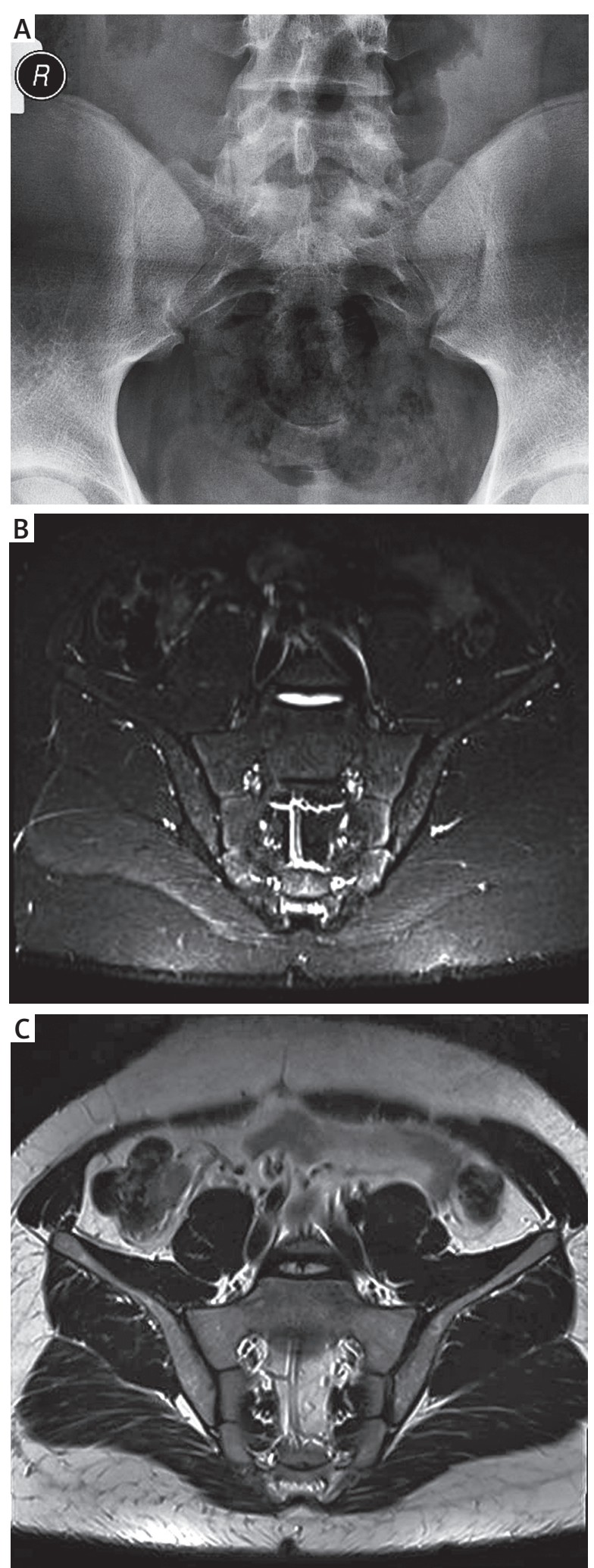

Fig. 4. Radiograph and MRI in a 17-year-old boy with a clinical diagnosis of sacroiliitis: radiograph: bilateral sacroiliitis, grade $2(A) ; M R I$, T2-weighted TIRM (B) and T2-weighted TSE (C): sacroiliac joints are intact. 
terms of inflammatory changes in the subchondral bone marrow and soft tissues (Fig. 5). According to data obtained from the observation of adult patients, inflammatory changes in the bone marrow and soft tissues seen on $\mathrm{MRI}$ can precede changes seen on radiographs by 3-10 years. Besides, MRI of the sacroiliac joints is capable of detecting other pathologies that might cause pain mimicking sacroiliitis. Our analysis has shown that protrusions or herniations in the lumbar spine (usually L3-S1 level) seen on MRI were present in as many as 16 (26\%) young patients. Moreover, 5 of them (8\%) presented horizontal orientation of the sacrum, and 2 presented ovarian cysts (4\%).

\section{Dynamic magnetic resonance imaging in psoriatic arthritis and juvenile spondyloarthropathies}

Dynamic contrast enhanced MRI has become an interesting area in diagnostic imaging of rheumatic diseases. The contrast agent is administered with a power injector. Such an examination allows quantitative assessment of inflammatory changes (Fig. 6). The usage of a power injector to administer a paramagnetic agent and subsequent multiple scanning at specific time intervals enable the analysis of signal intensity changes over time. Further, computer software (in the author's institution, the software used is Dynamika, Image Analysis Ltd, UK) allows automatic analysis of the image for each voxel and matches the type of enhancement to one of four patterns: no enhancement, persistent, plateau and wash-out. Having applied an algorithm that eliminates motion artefacts to the minimum, a radiologist selects slices and so-called regions of interest (ROIs) within the involved areas (joint cavity, tendon sheath or bone), then the software automatically calculates a number of quantitative data, such as: ME (maximum enhancement), IRE (initial rate of enhancement), GD (gadolinium) distribution and Tonset (time of onset) (Fig. 6A, C, $D)$. These parameters are presented in the form of color maps placed on an anatomic image, thus facilitating identification of affected regions.

Preliminary results of the author's own studies and literature reports indicate that parameters obtained in DCE-MRI correlate with laboratory and clinical findings. As inflammation clinically diminishes, the enhancement pattern is reported to change from plateau and washout (which is typical of inflammatory changes) to no enhancement and persistent (normal tissue). Furthermore, research studies indicate that DCE-MRI can deliver various data, such as maximum enhancement or gadolinium distribution, that might play a role in initial diagnosis, differentiation and monitoring of rheumatic diseases, affecting both peripheral and sacroiliac joints [28-30] (Fig. 6B).

Dynamic examinations are not often applied in clinical practice as they involve a power injector to administer the contrast agent, and above all the main aim is quantitative assessment of vascularisation, which does not always contribute to making clinical decisions. Thus in practice, the assessment of affected tissue is based on a qualitative analysis. Semi-quantitative scales are also rarely used because they are time-consuming. The OMERACT (Outcome Measures in Rheumatology Clinical Trials) group has proposed a system for assessment of inflammatory changes and destruction in joints of the
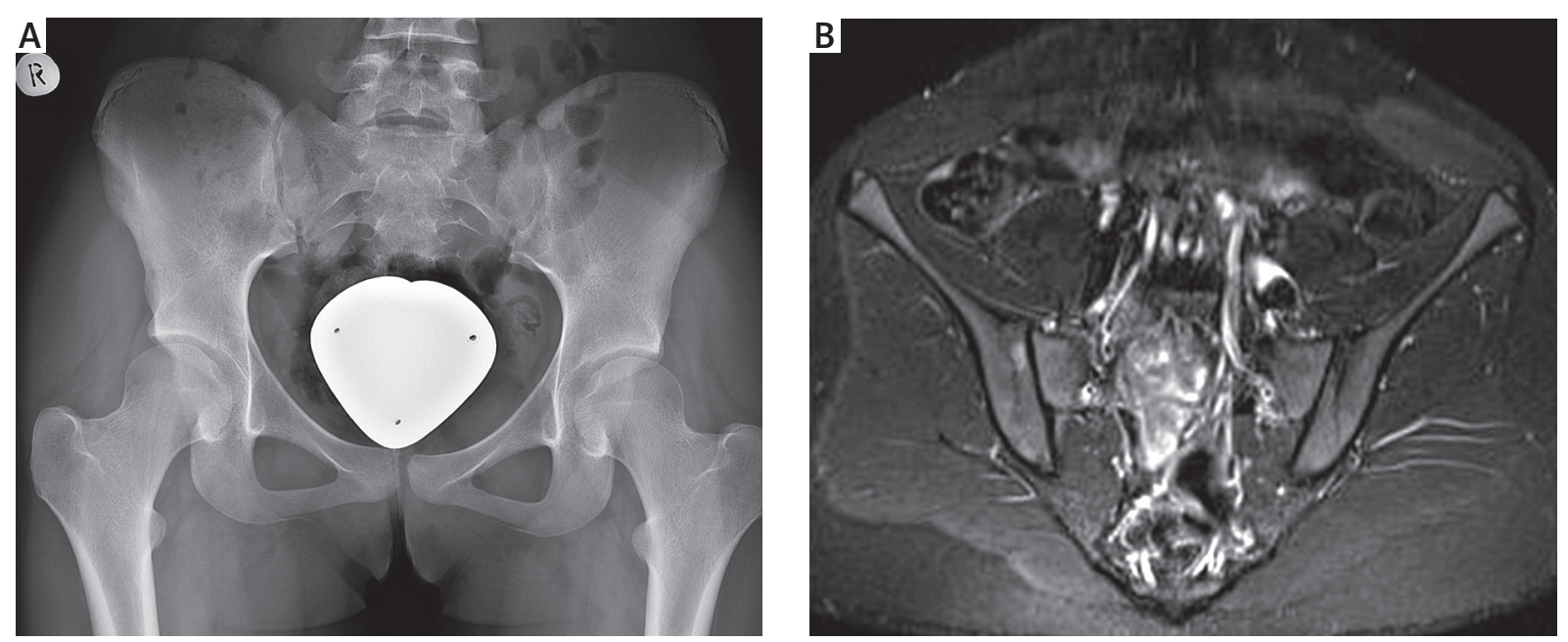

Fig. 5. Radiograph (A) and MRI of the sacroiliac joints, T2-weighted TIRM (B) in a 16-year-old patient with suspected sacroiliitis: no signs of inflammation on radiograph; MRI shows bone marrow edema in the ilium of the right sacroiliac joint. 

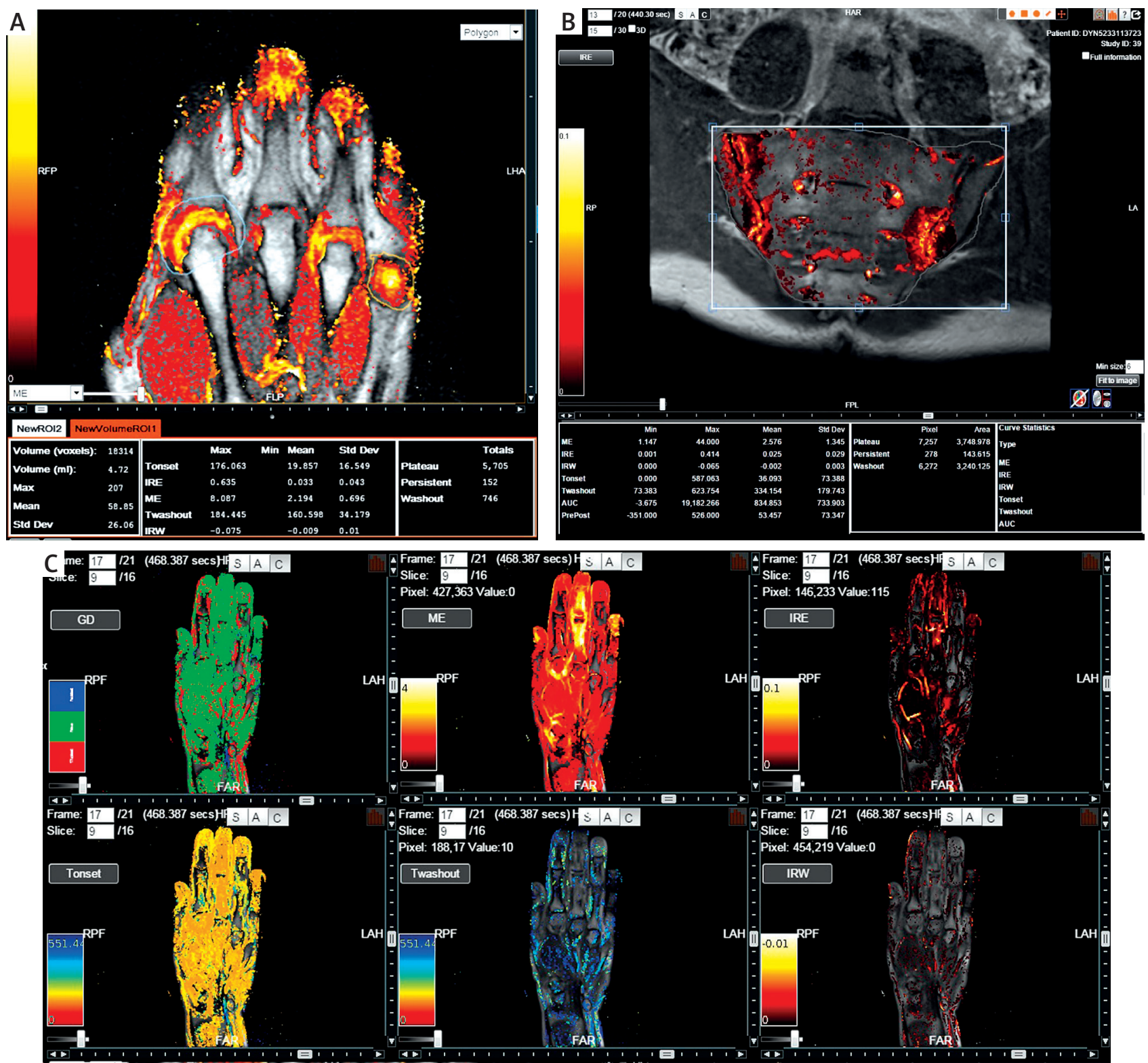

Fig. 6. Analysis of DCE-MRI of the hand in a patient with PsA using the Dynamika software (Image Analysis Ltd, UK): maximum enhancement (ME) map superimposed on the anatomic image with two regions of interest (MCP 2 and 5 joints); the table shows dynamic parameters (A); DCE-MRI analysis of of the sacroiliac joints in a patient with PsA using the Dynamika software: colored map of

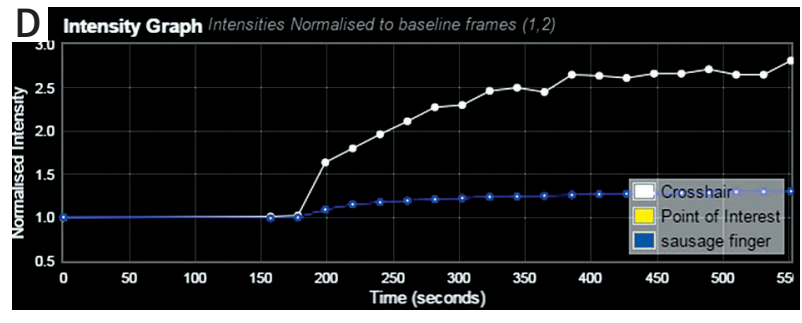

initial rate of enhancement (IRE) superimposed on the anatomic image shows inflammatory changes in the course of sacroiliitis; the table presents dynamic parameters (B); colored maps of dynamic parameters superimposed on an anatomic image of the hand; an ME map shows tenosynovitis in the flexor tendons of the $3^{\text {rd }}$ finger $(C)$; the diagram shows curves of enhancement over time after administration of a contrast agent; blue line - dactylitis; volumetric region of interest encompassing the whole finger; white line - region of interest within the inflamed synovium, at the site of the most intensive signal (D). 
hand in PSA, called PSAMRIS (psoriatic arthritis magnetic resonance imaging scoring system) [31]. The assessment involves metacarpophalangeal joints as well as the $2^{\text {nd }}-5^{\text {th }}$ distal and proximal interphalangeal joints for synovitis (score $0-3$ ), tenosynovitis (0-3), periarticular inflammation (present or absent), bone marrow edema (score 0-3), erosions (score 0-3) and presence of enthesophytes (visible or absent). This system, however, is not perfect. Strube et al. evaluated interobserver compatibility of the PSAMRIS scoring in a group of 65 patients with PSA on a 0.2T scanner. The study revealed low to moderate compatibility [32]. Østergaard et al. [31] and Ejbjerg et al. [33] conducted studies with low-fieldstrength scanners and confirmed discrepancies between observers in assessment of periarticular inflammation.

Poggenborg et al. [12] used DCE-MRI to monitor RA patients during anti-TNF therapy and found that MRI parameters improved during this treatment.

\section{Summary}

Plain radiography plays a role in the diagnosis of advanced PSA as it provides distinctive images of the underlying pathology [4]. The MRI and US enable early detection of inflammatory changes in peripheral joints, tendon sheaths and entheses. Furthermore, MRI presents inflammatory changes in the sacroiliac joints and axial spine [5]. In juvenile spondyloarthritis, there is a need for prospective studies involving MRI in order to establish diagnostic criteria for early stages of the disease.

Dynamic contrast enhanced MRI is a useful modality in the diagnostics of inflammatory changes in the course of PSA and JSPA. With the aid of advanced computerized technologies, it allows a readily, quantitative analysis of tissues affected by inflammation. Preliminary results suggest that definite patterns of contrast distribution can be useful in the differential diagnosis of rheumatic diseases, which, however, requires further investigation.

The authors declare no conflict of interest.

\section{References}

1. Coates LC, Hodgson R, Conaghan PG, et al. MRI and ultrasonography for diagnosis and monitoring of psoriatic arthritis. Best Prac Res Clin Rheumatology 2012; 26: 805-822.

2. Sieper J, Rudwaleit M, Baraliakos X, et al. The Assessment of SpondyloArthritis international Society (ASAS) handbook: a guide to assess spondyloarthritis. Ann Rheum Dis 2009; 68 (Suppl) 2: ii1-i44.

3. Brown AK. How to interpret plain radiographs in clinical practice. Best Prac Res Clin Rheumatol 2013; 27: 249-269.

4. Sudoł-Szopińska I, Matuszewska G, Kwiatkowska B, et al. Diagnostic imaging of psoriatic arthritis. Part I: etiopathogene- sis, classifications and radiographic features. J Ultrason 2016; 16: 65-77.

5. Sudoł-Szopińska I, Pracoń G. Diagnostic imaging of psoriatic arthritis. Part II: magnetic resonance imaging and ultrasonography. J Ultrason 2016; 16: 163-174.

6. Moll JM, Wright V. Psoriatic arthritis. Semin Arthritis Rheum 1973; 3: 55-78.

7. Helliwell PS, Taylor WJ. Psoriatic arthritis and psoriasis: classification, clinical features, pathophysiology, immunology, genetics. Classification and diagnostic criteria for psoriatic arthritis. Ann Rheum Dis 2005; 64: ii3-ii8.

8. Taylor WJ, Gladman D, Helliwell P, et al. Classification criteria for psoriatic arthritis: development of new criteria from a large international study. Arthritis Rheum 2006; 54: 2665-2673.

9. Narvaez J, Narvaez JA, de Albert M, et al. Can magnetic resonance imaging of the hand and wrist differentiate between rheumatoid arthritis and psoriatic arthritis in the early stages of the disease? Semin Arthritis Rheum 2012; 42: 234-245.

10. Schraml C, Schwenzer NF, Martirosian P, et al. Assessment of synovitis in erosive osteoarthritis of the hand using DCE-MRI and comparison with that in its major mimic, the psoriatic arthritis. Acad Radiol 2011; 18: 804-809.

11. Cimmino MA, Barbieri F, Boesen M, et al. Dynamic contrast-enhanced magnetic resonance imaging of articular and extraarticular synovial structures of the hands in patients with psoriatic arthritis. J Rheumatol Suppl 2012; 89: 44-48.

12. Poggenborg RP, Wiell C, Boyeses P, et al. No overall damage progression despite persistent inflammation in adalimumab-treated psoriatic arthritis patients: results from an investigator-initiated 48-week comparative magnetic resonance imaging, computed tomography and radiography trial. Rheumatology 2014; 53: 746-756.

13. Fournie B, Margarit-Coll N, Champetier de Ribes TL, et al. Extrasynovial ultrasound abnormalities in the psoriatic finger. Prospective comparative power-Doppler study versus rheumatoid arthritis. Joint Bone Spine 2006; 73: 527-531.

14. Tan AL, Grainger AJ, Tanner SF, et al. A high-resolution magnetic resonance imaging study of distal interphalangeal joint artropathy in psoriatic arthritis and osteoarthritis: are they the same? Arthritis Rheum 2006; 54: 1328-1333.

15. Scarpa R, Soscia E, Peluso R, et al. Nail and distal interphalangeal joint in psoriatic arthritis. J Rheumatol 2006; 33: 1315-1319.

16. Sudoł-Szopińska I, Kwiatkowska B, Prochorec-Sobieszek M, et al. Enthesopathies and enthesitis. Part 2: Imaging studies. J Ultrason 2015; 15: 196-207.

17. Jacques P, Lambrecht S, Verheugen E, et al. Proof of concept: enthesitis and new boneformation in spondyloarthritis are driven by mechanicals train and stromal cells. Ann Rheum Dis 2014; 73: 437-445

18. Poggenborg RP, Eshed I, Østergaard M, et al. Enthesitis in patients with psoriatic arthritis, axial spondyloarthritis and healthy subjects assessed by "head-to-toe" whole-body MRI and clinical examination. Ann Rheum Dis 2015; 74: 823-829.

19. Sudoł-Szopińska I, Zaniewicz-Kaniewska K, Kwiatkowska B. Spectrum of ultrasound pathologies of Achilles tendon, plantar aponeurosis and flexor digiti brevis tendon heel entheses in patients with clinically suspected enthesitis. Pol J Radiol 2014; 79: 402-408. 
20. Feydy A, Lavie-Bryon MC, Gossec L, et al. Comparative study of MRI and power Doppler ultrasonography of the heel in patients with spondyloarthritis with and without heel pain and in controls. Ann Rheum Dis 2012; 71: 498-503.

21. Paparo F, Ravelli M, Semprini A, et al. Seronegative spondyoarthropathies: what radiologists should know. Radiol Med 2014; 119: 156-163.

22. Sudoł-Szopinska I, Urbanik A. Diagnostic imaging of sacroiliac joints and the spine in the course of spondyloarthropathies. Pol J Radiol 2013; 78: 43-49.

23. Schueller-Weidekamm C, Mascarenhas VV, Sudoł-Szopińska I, et al. Imaging and interpretation of axial spondylarthritis: The radiologist's perspective-consensus of the arthritis subcommittee of the ESSR. Semin Musculoskelet Radiol 2014; 18: 265-279.

24. Sudoł-Szopińska I, Jurik AG, Eshed I, et al. Recommendations of the ESSR arthritis subcommittee for the use of magnetic resonance imaging in musculoskeletal rheumatic diseases. Semin Musculoskelet Radiol 2015; 19: 396-411.

25. Sheerin KA, Giannini EH, Brewer EJ, et al. HLA-B27-associated artropathy in childhood: long-term clinical and diagnostic outcome. Arthritis Rheum 1988; 31: 1165-1170.

26. Mandl P, Navarro-Compán V, Terslev L, et al. Eular recommendations for the use of imaging in spondyloarthritis in clinical practice. European League Against Rheumatism (EULAR) Congress 2014. Ann Rheum Dis 2014; 73: 427-428.

27. Sudoł-Szopińska I, Kwiatkowska B, Włodkowska-Korytkowska $M$, et al. Diagnostics of sacroiliitis according to ASAS criteria: a comparative evaluation of conventional radiographs and MRI in patients with a clinical suspicion of spondyloarthropathy. Preliminary Results. Pol J Radiol 2015; 80: 266-276.

28. Malattia C, Damasio MB, Basso C, et al. Dynamic contrast-enhanced magnetic resonance imaging in the assessment of disease activity in patients with juvenile idiopathic arthritis. Rheumatology (Oxford) 2010; 49: 178-185.

29. Axelsen MB, Poggenborg RP, Stoltenberg M, et al. Reliability and responsiveness of dynamic contrast-enhanced magnetic resonance imaging in rheumatoid arthritis. Scand J Rheumatol 2013; 42: 115-122.

30. Wang R, Dong Y, Zhong L, et al. Feasibility of DCE-MRI in the Detection of active lesions of ankylosing spondylitis in the sacroiliac joint. Radiological Society of North America 2014 Scientific Assembly and Annual Meeting, Chicago IL.

31. Østergaard M, McQueen F, Wiell C, et al. The OMERACT Psoriatic Arthritis Magnetic Resonance Imaging Scoring System (PsAMRIS): definitions of key pathologies, suggested MRI sequences, and preliminary scoring system for PsA hands. J Rheumatol 2009; 36: 1816-1824.

32. Strube H, Becker-Gaab C, Saam Tet, et al. Feasibility and reproducibility of the PSAMRIS-H score for psoriasis arthritis in low-field-strength dedicated extremity magnetic resonance imaging. Scand J Rheumatol 2013; 42: 379-382.

33. Ejbjerg BJ, Narvestad E, Jacobsen S, et al. Optimised, low cost, low field dedicated extremity MRI is highly specific and sensitive for synovitis and bone erosions in rheumatoid arthritis wrist and finger joints: comparison with conventional high field MRI and radiography. Ann Rheum Dis 2005; 64: 12801287. 